\title{
THE IDENTIFICATION OF THE DYNAMIC MODEL IN THE MINING PRESSURE REGIME IN ORDER TO ASSURE THE STABILITY OF THE UNDERGROUND MINING CONSTRUCTIONS
}

\author{
Associate Prof. eng. ${ }^{1}$ Victor Arad D.Sc.; Associate Prof. eng. ${ }^{1}$ Susana \\ Arad D.Sc.; Assistant eng. ${ }^{1}$ Monica Radulescu; ${ }^{2}$ Dana Cosma \\ ${ }^{2}$ Petrosani University, Romania, ${ }^{2}$ The West Lniversity of Timisoara, Romania
}

\begin{abstract}
The paper presents some theoretical considerations regarding the evaluation of the underground mining constructions' stability and practical aspects about identifying experimentally the dynamic regime of the pressure. The identification represents an experimental technique to determinate the dynamic models of the process, an important stage in designing and implementing an elastic performing supporting
\end{abstract}

Keywords: identifying, dynamic, mining pressure, stability, underground construction.

\section{INTRODUCTION}

The restructuring process aiming to make the economic activity more efficient has marked the mining reform.

In the future the coal mining will function in certain competitively conditions, reducing the production costs. The costs can be reduced mainly by reducing the costs of the supporting in mining constructions and also by improving their parameters.

The improvement of the actual supporting parameters and the designing of new supporting models relies on a deep knowledge about the working conditions, able to create an interdependence between the forms of the mining pressure and the stability of the rock massive and the supporting parameters.

The complexity of the phenomenon during the interaction process between rocksupporting system, determined by the great number of parameters, does not allow the complete description of the systems, their modeling using evaluation models. Thus, for most of the practical situations, parametrical models have to be accepted, a direct identification of the models being necessary.

Such interdependence claims knowledge about the geomechanic conditions of the underground constructions.
The accuracy of designing and optimizing the supporting parameters depends on the interaction model between the rock massive and the supporting system.

The dynamic models of the processes describing the relations between the command variations (depth of the mining work, its shape) and the output variations (rock pressure, rocks displacement around the contour of the mining work), also taking in account the numerous perturbations (physical-mechanical characteristics of the rocks), [1] [2].

\section{THEORETIC CONSIDERATIONS ABOUT EVALUATING THE STABILITY OF THE UNDERGROUND MINING CONSTRUCTIONS}

In order to analyze the geomechanic conditions of the rocks in the Jiu Valley, some parameters evaluating the stability of the mining constructions have been considered.

The geomechanic conditions regarding the position of the underground mining constructions have been included in a general geomechanic classification; this classification has a practical value when 
choosing the interaction models and the prognosis of the mining pressure regime.

The geomechanic classification regarding the conditions the position of the mining constructions is shown in Table no. 1.

\section{DATA ACHIEVEMENT AND IDENTIFICATION ÖF THE PROCESS}

In order to determine the pressure regime, an underground mining construction with an opening of $5 \mathrm{~m}$, situated at $900 \mathrm{~m}$ deep from the surface, placed in argillaceous gritstones, has been chosen After the measurements and the laboratory studies the result show a medium stability of these rocks.

Two stations measuring the mining pressure have been placed in this mining construction. The first one functioned according to the dynamometric principle and the second one to the hydraulic principle.

Table no. 1

\begin{tabular}{|c|c|c|c|}
\hline $\begin{array}{c}\text { Duration } \begin{array}{c}|c| \\
\text { from } \\
\text { The } \\
\text { beginning of } \\
\text { supporting } \\
\text { [days] }\end{array} \\
\text { station }\end{array}$ & $\begin{array}{c}\text { Dydraulic } \\
\text { Station }\end{array}$ \\
\cline { 2 - 4 } & $\begin{array}{c}\text { P } \\
\text { [MPa] }\end{array}$ & U [mm] & P[MPa] \\
\hline 0 & 0 & 0 & 0 \\
\hline 1 & 0.42 & 1.9 & 0.29 \\
\hline 2 & 0.484 & 4 & 0.5 \\
\hline 5 & 0.675 & 10 & 0.59 \\
\hline 6 & 0.8917 & 16.2 & 0.852 \\
\hline 7 & 0.917 & 16.3 & 0.907 \\
\hline 8 & 1.0191 & 20.2 & 1.0 \\
\hline 9 & 1.1592 & 25 & 1.125 \\
\hline 12 & 1.9108 & 49.3 & 1.734 \\
\hline 16 & 1.9745 & 50.8 & 1.859 \\
\hline 20 & 2.0509 & 52.8 & 2.011 \\
\hline 23 & 2.2292 & 60.3 & 2.1947 \\
\hline 27 & 2.484 & 66.2 & 2.3594 \\
\hline 30 & $2.5+77$ & 68.1 & 2.362 \\
\hline 34 & 2.5477 & 68.1 & 2.394 \\
\hline 40 & $2.5+77$ & 68.1 & 2.4115 \\
\hline & & & \\
\hline
\end{tabular}

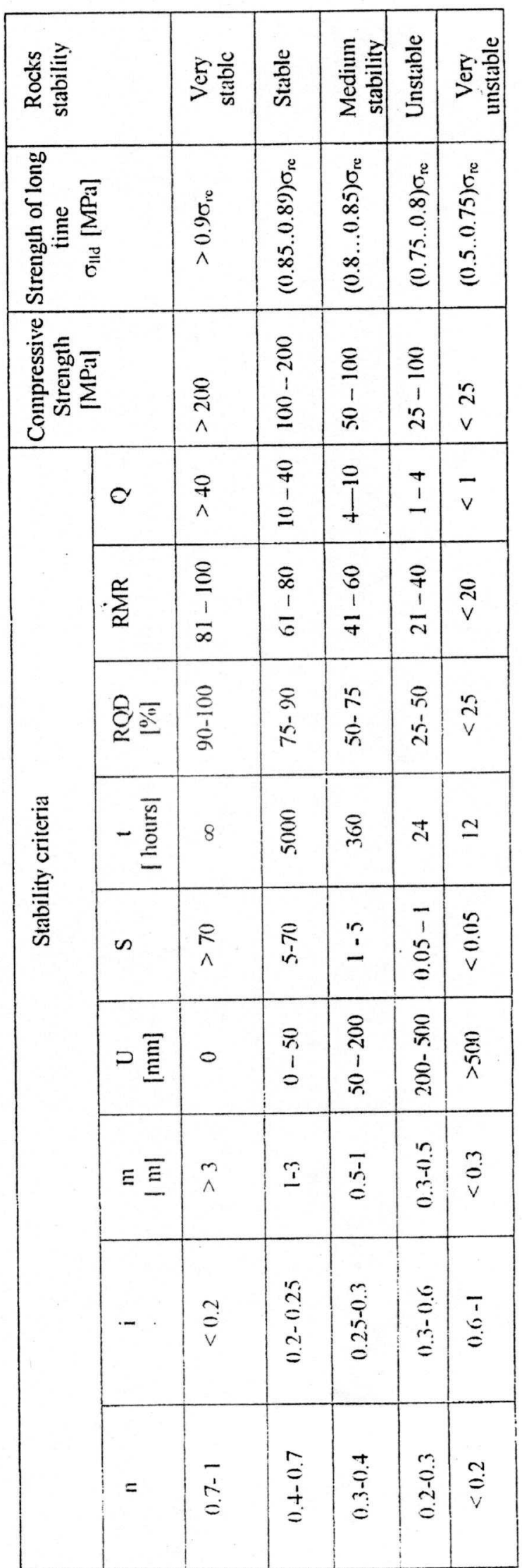

Table no.2 
Figure No. 1

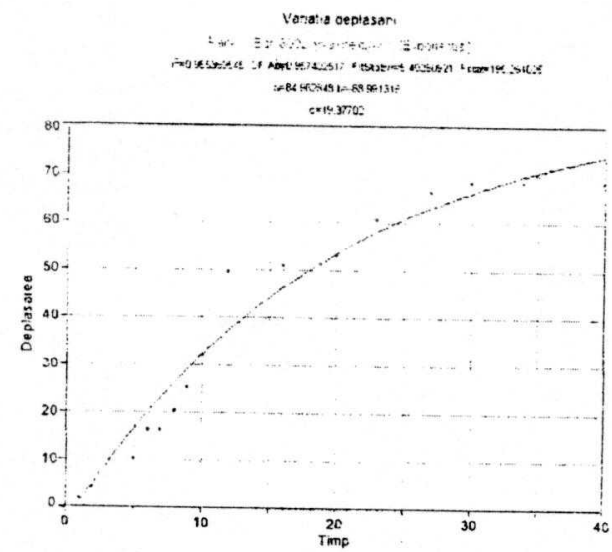

Figure No. 2

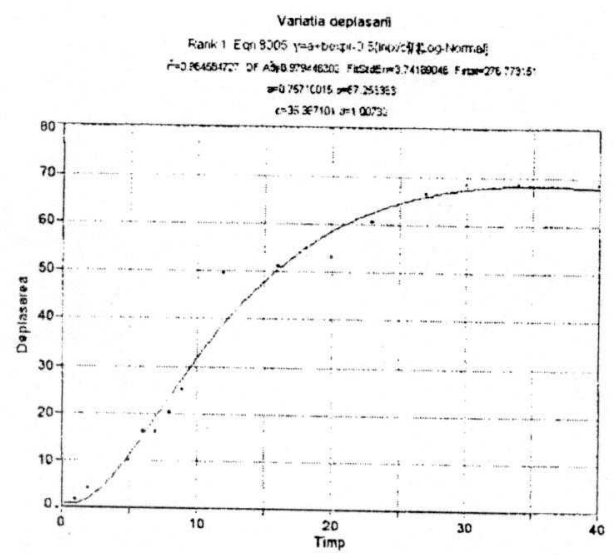

Figure no. 3

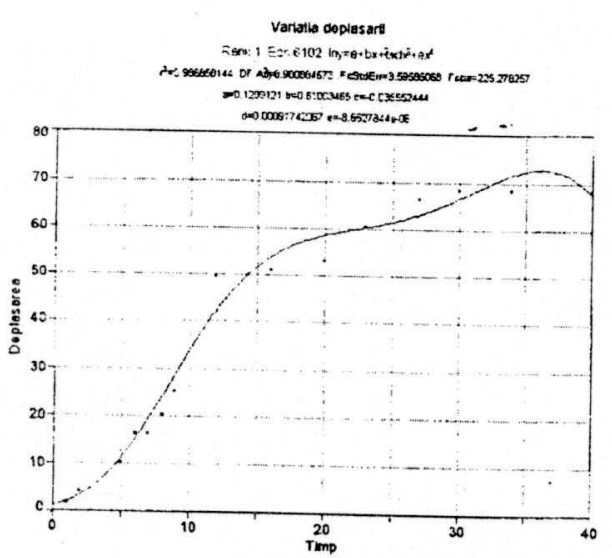

The variation pattern of the mining pressure depending on time is shown in Table no. 2

Besides the values of the mining pressure in the dynamometric measuring stations it also has been measured the rocks movement on the contour. The paper presents the processing of the experimental results, the output elements and the simulation of the pressure regime behavior, evaluating analytically the stability of the studied mining work.

Using the results and proper software, diagrams regarding the rock's displacements in time were obtained, as shown in fig. no. $1,2,3$. We also established the equations describing the pressure values depending on time and on the rock displacements in the underground mining construction contour.

The equations have been selected from a number of 308 equations, according to the results obtained by computing simulation.

\section{PRACTICAL ASPECTS OF IDENTIFYTNG THE PROCESS}

The dependence of the rock's displacements on the contour in time is described by a polynomial function obtained from the computing calculation of the measured data. This function has been selected from a number of 308 equations fitting the best the phenomenon described by the data measurements inserted in table no. 1. Fig. No. 2 shows that the function selected from a number of 40 equations is an exponential one. Fig. No.3 represents a rational function selected from a number of 48 equations.

Taking in account the random character of some perturbations of the dynamic system rock-support making the modeling process very difficult, the solution is obtained by using a numeric computer in order to implement the estimating algorithms of the modeling parameters. Therefore, using the TABLE- CURVE software, a calculation of the statistical indicators associated to the random variable characterizing the evolution of the system has been realized. 
All the calculated indicators for the processing of the 308 equations using the polynomial equation are shown in Table no. 3.

Taking in account the presented mathematical models [1] and also the geomechanic characteristics related to the rocks from the Jiu Valley region, a model of the pressure regime has been realized through an experimental identification the model allows the correlation and the correct option regarding the type of support.

\section{CONCLUSIONS}

Besides knowing the value of rock pressure it is necessary to know the manner of rock displacement on the contour.

Practical measurements have revealed that in the manifestation process of mine pressure regime, several stages can be distinguished in time:

$>$ the first stage corresponds to the period following shortly after the sinking stage when the rock pressure is low; this is followed by the period when rock pressure on the support increases very much, attaining maximum values, comprised between 1.3 and 2.6 MPa;

$>$ the next stage after a 30 to 45 days' period is characterized by a stabilization of the rock pressure regime;

after this stage follows one which is determined by the plastic behavior of the hard rocks;

The value of rocks forming around the mine workings depends on the geomechanic and rheologic characteristics of the rocks, the load- bearing capacity and rigidity of supports.

Underground observations have constituted the main investigations means and have been meant to gain knowledge of the singular and cumulative effects of various influence factors and have also referred to the steps that can be taken with a view to increasing the stability and reliability of development workings.
Table No. 3

$\begin{array}{lll}\text { Rank } \quad 1 & \text { Eqn } & 6102 \\ \ln y=a+b x+c \times 2+d \times 3+e x 4 & & \end{array}$

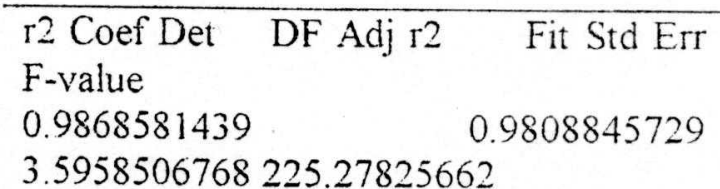

Parm Value Std Error t-value
95\% Confidence Limits

$\begin{array}{lll}\text { a } & 0.129912104 & 0.004996439\end{array}$

$\begin{array}{llll}26.00093763 & 0.119007751 & 0.140816457\end{array}$

$\begin{array}{lll}\text { b } & 0.610034650 & 0.023358332\end{array}$

$\begin{array}{llll}26.11636167 & 0.559056846 & 0.661012453\end{array}$

$\begin{array}{llll}\text { c } & -0.03555244 & 0.002889472 & \text { - }\end{array}$

$12.3041320-0.04185850-0.02924639$

$\begin{array}{lll}\text { d } & 0.000917421 & 0.000111456\end{array}$

8.2311999680 .0006741750 .001160666

e $\quad-8.6528 \mathrm{e}-06 \quad 1.35569 \mathrm{e}-06 \quad$.

$6.38257986-1.1611 \mathrm{e}-05 \quad-5.6941 \mathrm{e}-06$

Area Xmin-Xmax Area Precision

$1948.0996108 \quad 1.128172 \mathrm{e}-12$

Function min $\mathrm{X}$-Value Function $\max X$-Value

1.1387282890

$1.29967 \mathrm{e}-10$

$72.630156762 \quad 36.303734730$

1st Deriv min X-Value 1st Deriv

max X-Value

$-3.078765310$

$4.8015145194 \quad 8.7326025232$

2nd Deriv min $X$-Value 2nd Deriv

max X-Value

$-1.009725761$

40.000000000

0.6608758105

3.8027287810Soln

Vector Covar Matrix SVD Cond

SVDecomp

$9.977188 \mathrm{e}+14$

SVDecomp

\begin{tabular}{|c|c|c|c|c|}
\hline $\begin{array}{l}\text { r2 Coe } \\
0.9868 \\
3.5958\end{array}$ & $\begin{array}{l}\text { Det DF } \\
581439 \\
506768\end{array}$ & & $\begin{array}{l}\text { Fit S } \\
0.980\end{array}$ & $\begin{array}{l}\text { Err } \\
845729\end{array}$ \\
\hline $\begin{array}{l}\text { Source } \\
\text { Square }\end{array}$ & Sum of & & DF & Mean \\
\hline $\begin{array}{l}\text { Regr } \\
225.27\end{array}$ & 11651.515 & 4 & & 12.8799 \\
\hline Error & 155.16171 & 12 & & 30142 \\
\hline Total & 11806.681 & 16 & & \\
\hline
\end{tabular}




\section{$X$ Variable: Time \\ Xmin: 0.0000000000 \\ 40.000000000 Xrange: 40.000000 \\ Xmean: 14.117647059 \\ 12.712603751 Xmedian: 9.0000000000 \\ X@Ymin:0.0000000000 X@Ymax: \\ 30.000000000 \\ 30.000000000}

Y Variable: Displacement

Ymin: 0.0000000000

68.100000000 Yrange: 68.100000000

Ymean: 33.958823529

27.164638292 Ymedian: 25.000000000

Y@Xmin:0.0000000000 Y@Xmax:

68.100000000 Y@Xrange: 68.1000000

\section{EXPLANATORY}

- The mining pressure represents the total amount of the actions generated by the redistribution of the natural tension regime in the rock massif containing a mining work, actions producing displacements and deformations in rocks and supporting system.

- Pressure state is a consequence of the action of the gravity, tectonic, residual, water forces in time.

- The behavior of the underground mining constructions and the mining works stability depends on the geologicalmining conditions, on the geomechanical rock characterističs, with the interaction between the rock massive-supporting system as an effect.

- The stability evaluation criteria have an analytical expression appreciating the

degree of the rocks "stability depending on various parameters: physicmechanical characteristics, fissuration grade, the depth of the massif rock and so on.

- The mining supporting represents a system designed to assure the stability of the underground constructions.

- The mining supporting takes over the rocks' pressure state aiming to assure the stability of the mining work.

\section{REFERENCES}

[1] V. Arad "Establishing a Mathematical Model for determining Rock Pressure under the Difficult Conditions of the Valea Jiului" Proc. of International Conference, ITA, Budapesta, pp $40-42,1993$.

[2] V. Arad. "Study of the pressure regime and the selection of the most rational support types and technologies in the conditions of mining depth increase in the Valea Jiului", Doctoral thesis. Petrosani., 1992

[3] C. Hirian. "Researches concerning the stress mechanism and the interaction of the support with the surrounding rocks by the modeling method." Research Grant no. 491/MCT Bucuresti. 1994-

[4] I. D. Landau."System Identification and Control", Ed. Tehnica, Bucuresti 1997 